\title{
Meteorological Analysis of the Relationship between Climatic Parameters: Understanding the Dynamics of the Troposphere
}

Emmanuel P Agbo ( $\nabla$ emmanuelpaulagbo@gmail.com )

Cross River University of Technology https://orcid.org/0000-0002-0215-2492

Collins Edet

University of Port Harcourt

\section{Research Article}

Keywords: equivalent potential temperature, refractivity, meteorological analysis, Mann-Kendall trend analysis, climatic parameters, correlation matrix and pair plots

Posted Date: July 15th, 2021

DOI: https://doi.org/10.21203/rs.3.rs-662900/v1

License: (c) (i) This work is licensed under a Creative Commons Attribution 4.0 International License.

Read Full License 


\title{
Meteorological Analysis of the relationship between Climatic Parameters: Understanding the dynamics of the troposphere
}

\author{
Emmanuel P Agbo ${ }^{\mathrm{a}, \mathrm{b} * \dagger}$ and Collins O. Edet ${ }^{\mathrm{c}}$ \\ ${ }^{a}$ Department of Physics, Cross River University of Technology, Calabar, Nigeria \\ ${ }^{b}$ Faculty of Clinical Sciences, College of Health Sciences, Osun State University, Osogbo, \\ Osun State, Nigeria \\ ${ }^{c}$ Theoretical Physics group, Department of Physics, University of Port Harcourt, Port \\ Harcourt, Nigeria
}

\begin{abstract}
Understanding the relationship between the variations of meteorological parameters is vital in tackling the climatic problem. This paper presents methods for analyzing parameters that relate directly and indirectly to each other and accurate methods for interpreting their results. Using obtained data for 14 years and calculated data for other parameters, we adopt the Mann-Kendall (M-K) test for the trend analysis of the annual and seasonal variations, the correlation matrixes, and linear regression pair plots to discern the relationship between all parameters using the python programming software. To crystalize results, partial derivatives relating the equivalent potential temperature (EPT) for a pseudo-adiabatic process with parameters affecting its variation from equations are being obtained. The magnitude of these derivatives' gradients was used to bolster regression results, showing the mixing ratio (MR) of air as the parameter with the most effect on EPT variation. The MK test results show that the atmospheric pressure (AP) and average ambient temperature (AT) were all increasing significantly for all variations (annual, dry and wet seasons). In contrast, others varied between dry and wet seasons after adopting a benchmark significance level of 5\% (0.05). The correlation matrixes and linear regression pair plots show a strong relationship between the variations of refractivity, EPT, the temperature at the lifting condensation level (TL), MR, vapor pressure (VP), specific humidity (SH), and the dew point temperature (DPT). The potential temperature (PT), saturated vapor pressure (SVP), saturated mixing ratio (SMR), and the AT relationships showed a robust positive correlation/regression. This correlation offers a connection between the AT and the PT. The processes, including the partial derivatives, pair plots, correlation matrixes, and tests for trends, provide a solution to the meteorological analysis problem. Results and methods can be applied in other regions.
\end{abstract}

Keywords: equivalent potential temperature; refractivity; meteorological analysis; Mann-Kendall trend analysis; climatic parameters; correlation matrix and pair plots

\section{Running head:}

\footnotetext{
*Corresponding author. Emmanuel P. Agbo

†E-mail: emmanuelpaulagbo@gmail.com

Telephone: +2347018774580

Postal Address: 540242

ORCID: 0000-0002-0215-2492
} 


\author{
Abbreviations \\ EPT Equivalent potential temperature \\ ET Equivalent temperature \\ PT Potential temperature \\ MT Maximum temperature \\ $T_{L} \quad$ Absolute temperature at the lifting condensation level \\ MR Mixing ratio \\ SMR Saturated mixing ratio \\ VP Vapour pressure \\ SVP Saturated vapour pressure \\ DPT Dew point temperature \\ SH Specific humidity \\ RH Relative humidity \\ AT Average Temperature \\ AP Armospheric pressure \\ M-K Mann-Kendall \\ SSE Sen's slope estimator \\ p-value probability value \\ EM Electromagnetic \\ VHFs Very high frequency(ies) \\ ITU Intermational Telecommunication Union
}

\title{
$1 \quad$ Introduction
}

An understanding of how meteorological parameters relate to each other is one of the fundamental requirements in climatology. In-depth knowledge of their variations is vital in not just understanding climate change but curbing it. Discerning the seasonal, annual, monthly, and even daily variations of the basic parameters can serve as a building block to interpreting and forecasting weather.

Effects ranging from radio signal propagation, extreme humidity, air pollution (Akpinar et al. 2008; Fang et al. 2007), fungal spores in the air (Grinn-Gofron and Strzelczak, 2011; Grinn-Gofron and Bosiacka, 2015), etc., are all a result of this. An understanding of how all these parameters relate to each other cannot be overemphasized. Some parameters directly affect others, while some relate to each other, mainly because they have the same fundamental relationship. For example, Agbo et al. (2020) explained with theoretical proof what we know; relative humidity is related to the atmospheric vapor pressure. However, the relationship is not too direct; they are related to the atmosphere's water vapor contents.

In their review paper Agbo et al., (2021a) highlighted the importance of understading the trends of temperature which is related to solar radiation for effective electricity generation.

Understanding these variations, together with their relationship (correlation), will help researchers understand how and to what percentage these parameters affect each other. This understanding is necessary to comprehend things like radio wave networks' accurate performance when they are at very high frequencies (VHFs) (Adediji et al., 2014).

Studies have been carried out to buttress radio wave propagation (Agbo et al., 2021b; Agbo 2021; Adediji et al. 2011; Kim et al. 2014) to discern the variation of radio refractivity as affected by some meteorological parameters including RH, AP and average ambient temperature (AT). This study will handle this area and go deeper by studying more parameters whilst trying to find the link between all of them, including the dew point temperature (DPT), the specific humidity (SH), the saturated vapor pressure (SVP), the vapor pressure (VP), the saturated mixing ratio (SMR), the mixing ratio of air (MR), the absolute temperature at the lifting condensation level $\left(T_{L}\right)$, the potential temperature (PT), the equivalent potential temperature (EPT) and how they relate with each other. This study is relatively novel as the relationship between the parameters like refractivity, EPT, etc., has not been deeply understood. The EPT for a pseudo-adiabatic process takes into account the AT, AP, MR, VP (relating to 
RH), SMR $T_{L}$, and PT; approximate solutions of the EPT for a pseudo-adiabatic process are being adapted from Bolton (1960). We will be adopting the non-parametric M-K test to study the annual, dry season, and rainy (wet) season variations and the relationship between all the parameters mentioned above in these seasons.

Hypothetically, studying the atmosphere (specifically the troposphere) is like looking at a prism with an almost unity index of refraction (Agbo et al. 2020); this "almost unity" index of refraction, although negligible, has enormous effects on the climatic conditions of a region.

The M-K test is a famous test for time series variations and is majorly applied in climatology and related studies (Roboaa and Al-Barazanji, 2015; Mondal et al. 2012; Atta-ur-Rahman and Dawood 2017; Kisi and Ay., 2014) to understand the significance (if any) of the increasing (positive Kendall Z statistic value) or decreasing (negative Kendall Z statistic value) variations (Chattopadhyay et al. 2012). We will apply this test method to understand the trend of each parameter over time individually.

We can understand the significance of the trend (increasing or decreasing) by noting the significance level $(\alpha)$. We have a significantly growing trend when the observation's p-value is less than $\alpha$; the trend here is said to reject the null hypothesis, which means that there is a trend in the series. Consequently, we have a significantly decreasing trend when the observation's p-value is less than $\alpha$. (Alhaji et al., 2018). The movement here is said to accept the null hypothesis, which means no trend is in the series being analyzed.

This test has been applied by Agbo (2021) in his study after taking advantage of the pymannkendall package of the python programming language. He studied the variation of maximum temperature in southern Nigeria for the annual and seasonal (dry and wet season) variations. Results show a positive Z-value showing an increasing maximum temperature trend for all these seasons $(2.52,3.23,4.05$, respectively). These showed that the wet season had the highest increase over the years. The p-values for all variations were less than the level of significance (0.05), showing that the increasing trend had no significance.

We aim to achieve this research's objectives as the meteorological parameter's theory has been studied, including refractivity and EPT. The time-series analysis tool (the M-K test) too, all reviewed in section 2.

The present research article is organized as follows, in section 2, we review the theory of refractivity as it relates to all obtained (AT, AP, and RH) and calculated meteorological parameters (SVP and VP), EPT relating to the MR of air, SMR, $T_{L}$, PT, etc. We also go ahead to review the time series analysis technique, the M-K test, and relating it to the SSE; Sen (1968). We delve deeper into the methodology in section 3 by describing the region of study and her climatic conditions. The data collection method and the data processing tools and techniques were elaborated here. We also reviewed equations for parameters like the DPT and the SH.

In section 4, seasonal trends for all the aforementioned meteorological parameters are plotted every month for all the years in the study; this was done for the dry and wet seasons. The relationship between all the study parameters was discerned, focusing on the parameters that have a direct relationship with each other. This relationship was determined using correlation matrixes (annual and monthly) and linear regression pair plots. Partial differentials were also used to understand the effect of some parameters variation on the change in others. The M-K test is also adopted and used to test for trends for the annual, dry, and wet season variations. All results were adequately discussed, and facts were drawn. We give our concluding remark in section 5.

\section{Theoretical Background}

\subsection{Refractivity Theory}

All EM waves must obey the inverse square law (Javeed et al., 2018; Oyedum 2008), where the radiated wave will have a value that is reduced quadratically with the increase of distance away from the source. These EM waves will be reflected, refracted, etc.

Refractivity, which we will be partly studying, is coined from the refractive index $n$, which is related to the speed of the signal in free space $V_{f}$ and the speed of the signal in the specified medium $V_{m}$ (in this case the atmosphere) as (Javeed et al. 2018; Oyedum 2008);

$n=\frac{V_{f}}{V_{m}}$

The signal's speed in the atmosphere will be less than that in free space because some parameters impede the speed of the EM wave in the atmosphere. Therefore, the ratio in equation (1) cannot be unity, but a little bit more. According to (Chinelo and Chukwunike 2016), these values are higher in the troposphere while they reduce to unity as we increase in altitude in the atmosphere.

Refractivity and refractive index is related by (Ojo et al. 2015); 
$N=(n-1) \times 10^{6}(N-$ Units $)$

Given the value of $n$, we can obtain refractivity from equation (2) above. However, refractivity, which is measured with refractometers, can be calculated by the adoption of meteorological parameters including, the AP $(P)$ in $\mathrm{hPa}$, VP $(e)$ in $\mathrm{hPa}$, and the Absolute Temperature $\left(T_{k}\right)$ in Kelvin, with the equation recommended by the ITU and applied in various studies (Kaissasou et al. 2015; Ogunsua et al. 2018; Agbo 2021; Adediji et al. 2011; Faladun and Okeke, 2013; Ayantunji et al. 2011)

$N=77.6 \frac{P}{T_{k}}+3.73 \times 10^{5} \frac{e}{T_{k}^{2}}(N-$ units $)$

Careful observation of equation (3) above shows that refractivity is a summation of two terms, the dry $77.6 P / T_{k}$ and the wet term $3.73 \times 10^{5} \mathrm{e} / T_{k}^{2}$. The wet term contributes to more variation while the dry term contributes more to the total value with an almost constant variation (Agbo et al. 2020; Dairo and Kolawole 2017, Ayatunji et al., 2011; Alimgeer et al., 2018).

Equation (3) shows that the VP (e), is required to calculate refractivity; this term is related to the RH $(H)$;

$e=\frac{e_{s} H}{100}(h P a)$

$e_{s}$ here is the maximum or saturated vapour pressure (SVP) in hPa; calculated using Clausius-clapeyron relation; $e_{s}=6.11 \exp \left(\frac{17.26\left(T_{k}-273.16\right)}{T_{k}-35.87}\right)(h P a)$

where

$T_{k}$ is the Absolute temperature (K)

\subsection{Theory of Equivalent Potential Temperature (EPT) for a Pseudo-Adiabatic Process}

The EPT, which can also be called the potential equivalent temperature, represented by $\theta_{E}$ is related to parameters like; the temperature at the lifting condensation level $T_{L}$, the MR $(r)$, the PT $(\theta)$, the equivalent temperature, and the SMR $\left(r_{s}\right)$, etc. (Agbo et al. 2020; Bryan 1980)

Radio wave propagation in the atmosphere is affected by air parcels' movement through the atmosphere; this varies the atmospheric pressure. These changes lead to condensation; the temperature of an air parcel that is unsaturated will not condense, howbeit, a saturated air parcel will condense (Bolton, 2008). The processes for a saturated air parcel are irreversible.

A pseudo-adiabatic process is a saturated process; in this process, water released from condensation is released as heat or water vapor. Since this heat is not gained or lost (adiabatic process), the heat gets added back to the air parcel (Bechtold, 2009). This means that a saturated air parcel that passes through an adiabatic process losses heat at a much slower rate than unsaturated air.

We consider $T_{L}$ (the absolute temperature at the lifting condensation level); this is the temperature a given air parcel would attain if lifted dry adiabatically to its lifting condensation level. At the lifting condensation level, the dry air parcel becomes saturated after being raised adiabatically.

For accurate values of $T_{L}$, Bolton (1960) gives the relation to be;

$T_{L}=\frac{2840}{3.5 \operatorname{In} T_{k}-\operatorname{In} e-4.805}+55$

$e$ is the vapour pressure in $\mathrm{hPa}$

$T_{k}$ is the absolute temperature in kelvin

The vapour pressure is related to the mixing ratio of air by the relation;

$r=\varepsilon \frac{e}{P-e}$

where $\varepsilon=\frac{R_{d}}{R_{v}}=621.97$

$r=621.97 \frac{e}{P-e}$

$e$ is the vapour pressure, and $P$ is the atmospheric pressure. Similarly, the saturated mixing ratio can be represented as 


$$
r_{s}=621.97 \frac{e_{s}}{P-e_{s}}
$$

Using the mixing ratio $r$ and the absolute temperature $T_{k}$, the potential temperature $\theta$ can be obtained to be;

$$
\theta=T_{K}\left(\frac{1000}{P}\right)^{0.2854\left(1-0.28 \times 10^{-3} r\right)}
$$

This is the temperature in which an unsaturated air parcel would have had if it is lifted dry adiabatically to $1000 \mathrm{hPa}$.

The EPT $\theta_{E}$ is related to the temperature at the lifting condensation level $T_{L}$, the PT $\theta$, the MR $r$, the absolute temperature (in kelvin) $T_{k}$, and the atmospheric pressure P by (Bolton 1960; Davies-Jones 2009);

$$
\begin{aligned}
& \theta_{E}=T_{K}\left(\frac{1000}{P}\right)^{0.2854\left(1-0.28 \times 10^{-3} r\right)} \times \exp \left[\left(\frac{3.376}{T_{L}}-0.00254\right) \times r\left(1+0.81 \times 10^{-3} r\right)\right] \\
& =\theta \times \exp \left[\left(\frac{3.376}{T_{L}}-0.00254\right) \times r\left(1+0.81 \times 10^{-3} r\right)\right]
\end{aligned}
$$

We consider the variations of $C_{p d}$ (specific heat at constant pressure) with temperature and pressure. On that note, EPT can be defined as an air parcel's final temperature, which is attained when that air parcel is adiabatically lifted dry to its lifting condensation level $T_{L}$ (Bechtold, 2009). We should note that since this process is adiabatic, this happens without the loss or gain of heat. This will make all the moisture condense pseudo-adiabatically (concerning water saturation), then drop out the condensed water as it is formed. Finally, it is being brought down dry adiabatically to $1000 \mathrm{hPa}$ (Agbo et al., 2021b).

Understanding of the application of EPT and PT has been studued by Gao and Cao (2007) for the application in cyclone tracks in nonunifirmly saturated atmosphere, comparisons of generalized PT in a moist atmosphere with the EPT in a saturated moist atmosphere by Zhou et al. (2009), EPT and PT patterns at cold fronts with pre-fontal foehn by Hiemann (1992). This buttresses the importance of our study as it relates to other paraneters.

\subsection{Test for Trend (The Mann-Kendall Trend Test as Applied in the Analysis of Climatic Parameters)}

We use the M-K test when analysing time-series data. The test is non-parametric and does not require the data to conform to a particular distribution. (Agbo 2021)

We apply this test when a given range of data $x_{i}$ agrees with the relation (Salmi et al. 2002);

$x_{i}=f\left(t_{i}\right)+\varepsilon_{i}$

$f\left(t_{i}\right)$ here is a function of continuously increasing or decreasing monotonically, $\varepsilon_{i}$ are the range residuals.

In the M-K test, we test the null hypothesis $H_{o}$ which says that there is no trend, and the alternative hypothesis $H_{1}$ which means that there is a trend in the series. If the results gotten from the test agrees with the null hypothesis (meaning that there is no trend), it means that the given data $x_{i}$ is randomly ordered in time $(\mathrm{t})$, while the alternative hypothesis says that there is either an increasing monotonic or a decreasing monotonic trend.

The M-K test uses the statistic S, calculated using;

$S=\sum_{k=1}^{n-1} \sum_{j=k=1}^{n} \operatorname{sgn}\left(x_{j}-x_{k}\right)$

where;

$$
\operatorname{sgn}\left(x_{j}-x_{k}\right)= \begin{cases}+1 ; & \text { if }\left(x_{j}-x_{k}\right)>0 \\ 0 ; & \text { if }\left(x_{j}-x_{k}\right)=0 \\ -1 ; & \text { if }\left(x_{j}-x_{k}\right)<0\end{cases}
$$

The number of data values is represented by n. A positive $S$ value indicates an upward variation, and a negative $S$ value characterizes a downward variation. However, S's higher positive values suggest an increasing trend and lower negative values indicate a decreasing trend.

The normal approximation ( $Z$ statistic) is always used if the number of data values $n$ is from 10 and above. We should also note that when there are tied/equal values, the accuracy of using the $Z$ statistic will reduce if the data 
values are close to 10 .

To compute the value of the $\mathrm{Z}$ statistic, we obtain the variance of $S^{\prime} \operatorname{VAR}(S)$ ' (Agbo 2021)

$$
V A R(S)=\frac{1}{18}\left[n(n-1)(2 n+5)-\sum_{p=1}^{g} t_{p}\left(t_{p}-1\right)\left(2 t_{p}+5\right)\right]
$$

$g$ represents the number of tied groups in the series (showing that the test takes the tied or equal values into consideration. The number of data values in the $p^{\text {th }}$ the group is represented by $t_{p}$.

We can now obtain the test statistic Z, using the values of $\operatorname{VAR}(S)$ and $S$; (Agbo 2021)

$$
Z= \begin{cases}\frac{S-1}{\sqrt{\operatorname{VAR}(S)}} ; & S>0 \\ 0 ; & S=0 \\ \frac{S+1}{\sqrt{\operatorname{VAR}(S)}} ; & S<0\end{cases}
$$

The decreasing variation is discerned the $\mathrm{Z}$ value is negative, and an increasing trend is seen from a positive $\mathrm{Z}$ value. Both interpretations can be concluded to have a significant trend if and when the data's p-value is lower than the significance level $(<5 \%=0.05$ in this case $)$. The trend is not significant if the $p$-value is higher than the level of significance.

\section{Methodology for the Meteorological Analysis}

\subsection{Study Area}

Calabar, a coastal city and the Cross River State capital (Figure 1) and has a land area of approximately406 sq km (157 sq miles), is located at latitude $4^{\circ} 57^{\prime} 06^{\prime \prime} \mathrm{N}$ and longitude $8^{\circ} 19^{\prime} 19^{\prime \prime}$ E. Her primary climate type is the tropical monsoon climate contributed by her proximity to the Atlantic Ocean. The region elevates about $42 \mathrm{~km}$; this varies, but this is the approximate elevation. The region's proximity to the Atlantic Ocean' drives conventional waves to the area, making the area very humid' (Agbo et al. 2021b), which is related to high rainfall, expounded in studies by Agbo et al. (2020), Agbo and Ekpo. (2021), Agbo (2021) and Agbo et al. (2021b).

Throughout the year, the majority of the months in Calabar experience precipitation. The dry season lasts or about four months (November to February), characterized by the harmattan. There is a more extended period for the wet season (March to October); this makes the region's weather condition reasonably stable across the year.

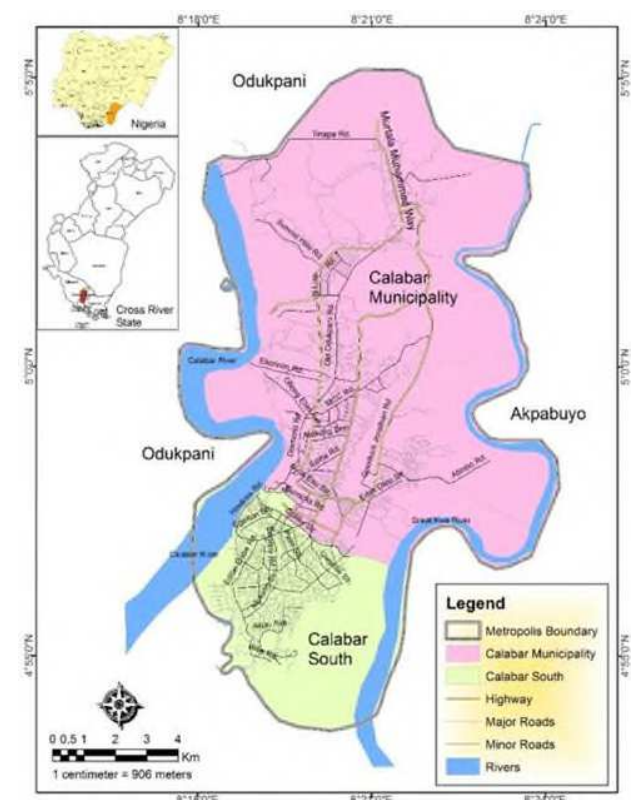

FIGURE 1: Map of the Study Area (Agbo 2021; Agbo and Ekpo. 2020)

\subsection{Data collection}

The minimum and maximum ambient temperature, RH, and AP were the only meteorological parameters obtained for 14 years from the Nigerian Meteorological Agency (NiMet) in Calabar. All other parameters were calculated 
from the obtained parameters.

The geographical location of NiMet Calabar is displayed in figure 2 at the Margaret Ekpo International Airport, Calabar.

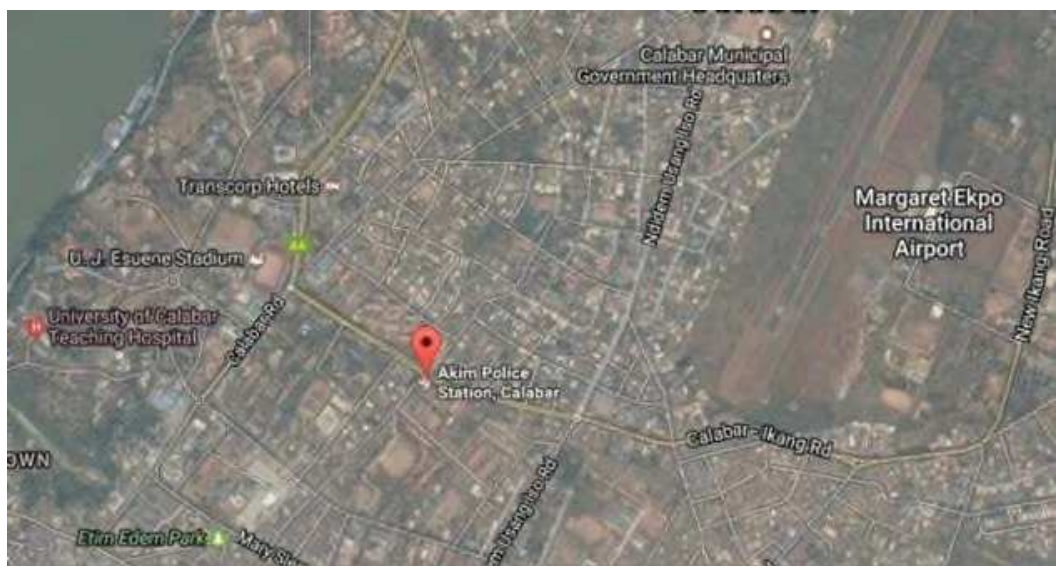

FIGURE 2: An overview of the Calabar metropolis, showing the location of NIMET at Margaret Ekpo International Airport (Agbo 2021; Agbo et al. 2020).

\subsection{Data Processing Method}

The obtained meteorological parameters from NiMet (The daily minimum and maximum temperature, $\mathrm{RH}$ and AP) were all utilized to get all other parameters. Their obtained daily values were averaged to get the monthly values. The average temperature value was obtained from finding the average of the minimum and maximum temperature.

The VP and the SVP were calculated using equations (4) and (5). These parameters were utilized with the obtained meteorological parameters to calculate refractivity using equation (3) rather than refractometers.

Parameters relating to the EPT were also utilized. The absolute temperature at the lifting condensation level $\left(T_{L}\right.$ ) the MR, the SMR, and the PT were all calculated using equations (6), (8), (9), and (10), respectively. The EPT utilized all these aforementioned parameters and was calculated using equation (11).

The DPT is related to the RH and temperature in Celsius by the relation;

$$
T_{D}=243.04 \times \frac{\operatorname{In}\left(\frac{R H}{100}\right)+\left(\frac{17.625 \times T}{243.04+T}\right)}{17.625-\operatorname{In}\left(\frac{R H}{100}\right)-\left(\frac{17.625 \times T}{243.04+T}\right)}
$$

The SH related to the mixing ratio was calculated using;

$q=\frac{r}{1+r}$

Where $q$ is the specific humidity and $r$ is the mixing ratio of air.

This study's analysis tool is the python programming software used with the Jupyter Notebook IDE. The Wolfram Mathematica software has also been adopted for getting partial differentials. The time series was studied using the M-K test to show the increasing or decreasing variation; this was done using the python software's pymannkendall package. The Kendall Z-values were computed without the software by using equation (16).

The M-K test was done for both the annual and seasonal variations. The wet season in the region was taken from March through to October (8 months), the dry season was taken from November through February (4 months). This was done to infer the difference and effects of both seasons on the variations of all parameters.

In addition to the M-K test results, descriptive and correlation tables were used to describe the data and show the relationship between them for the annual and monthly variation. Correlation matrixes and pair plots of linear regression were plotted to buttress the relationships between all parameters, showing which parameter affected the other's interpretation, or at least which parameters have related variations. 


\section{Results from the Meteorological Analysis of all Climatic Parameters}

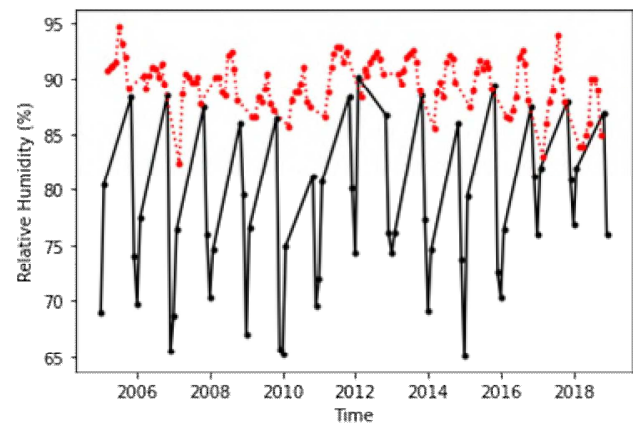

-... Dry season

FIGURE 3: Monthly time-series variation for relative humidity over the two seasons for the period 2005 - 2018

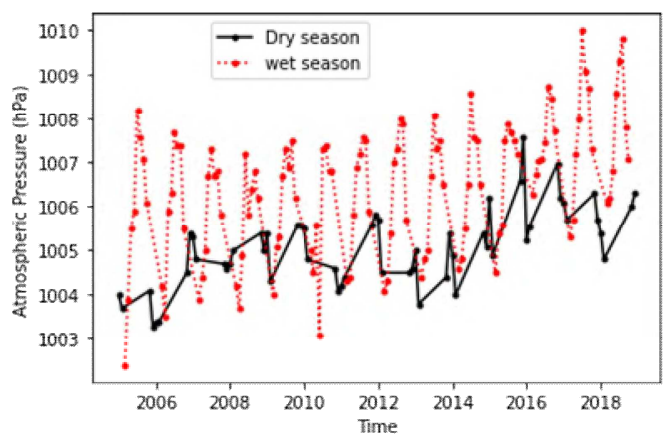

FIGURE 4: Monthly time-series variation for atmospheric pressure over the two seasons for the period 2005 2018

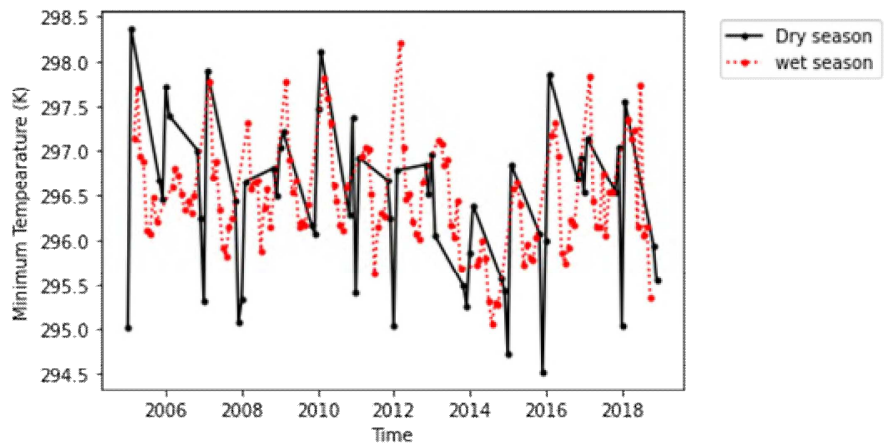

FIGURE 5: Monthly time-series variation for minimum temperature over the two seasons for the period 2005 2018

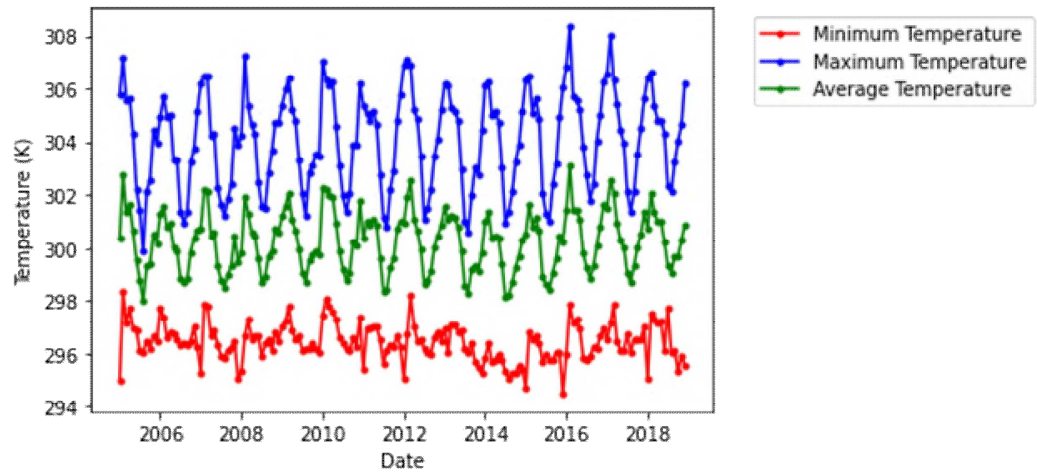

FIGURE 6: Monthly time-series variation for all temperature trends over 2005 - 2018, showing the deviation for each. 


\subsection{Results of the Mann-Kendall Trend Test}

[Table 1 about here.]

\section{- Annual Variation}

The annual variation of meteorological parameters has been detected using the $\mathrm{M}-\mathrm{K}$ test and summarized in table 1. Results show that most parameters did not have significant trends after their p-values were found to be greater than the significant level (0.05). The positive Z-value in the tables shows an increasing variation. In contrast, a negative Z-value shows a decreasing variation. The AP and MT both had a significant trend, increasing over the years. Howbeit, the AP trend had the most significant increase.

Only the minimum temperature and RH had decreasing variations, although their variation was not decreasing significantly ( $\mathrm{p}$-values $>0.05)$.

The AT, DPT, SH, SVP, VP, SMR, MR, $T_{L}$, PT, EPT and refractivity all had increasing variations. Still, none of them increased significantly after their p-values were greater than the significant level (0.05).

The annual variation shows that most of the analyzed parameters did not have significant trends, proving that the climatic condition in the region, although increasing, is almost uniform.

For the AP, the trend has the most significance (with p-value < 0.001), proving that Calabar is a coastal region with increasing pressure on her troposphere; this may be attributed to the constant humidity in the area arising from the long wet season. The wet season variation is discussed in the next subsection. The Kendall Z-value for AP was the highest $(Z=3.83)$.

[Table 2 about here.]

\section{- Wet Season Variation}

The variation of all obtained and calculated meteorological parameters for the wet season in Calabar has been analyzed using the M-K test for all years and presented in Table 2, the wet season data, analyzed for March through October (8 months).

Results show that the AP (p-value $<0.001$ ), relative humidity (p-value $<0.01$ ), minimum ( $\mathrm{p}$-value $<0.01$ ), and maximum (p-value $<0.001$ ) were all found to have significant trends, with the AP and MT having an increasing trend positive Kendall Z-values of 7.79 and 4.05 respectively. In contrast, the RH and minimum temperature both had negative Kendall Z-values (-2.89 and -2.29, respectively). The high positive Kendall Z-values of the AP for the wet season variation (observed in table 2) proves that the wet season contributes more to the increase in AP with the rise in the water vapor content of the atmosphere (troposphere).

All other obtained and calculated parameters analyzed did not have significant trends ( $\mathrm{p}$-values $>0.05$ ), albeit increasing variations were observed in the AT, SVP, SMR, and PT. Other variations were negative (decreasing) but were not reducing significantly ( $p$-values $>0.05$ ).

The decreasing variations of parameters like the RH, minimum temperature, DPT, SH, VP, MR, the $T_{L}$, EPT, and refractivity show that the wet season does not contribute to the increase in their variations over the years. Howbeit, the decrease is significant for that of relative humidity and minimum temperature.

[Table 3 about here.]

\section{- Dry Season Variation}

The results from the analysis of the variations of all obtained and calculated parameters for the dry season in Calabar are shown in table 3. November through February are the months of the dry season in the region; the results were continuously analyzed for all years for these four (4) months.

Compared to other variations (annual and wet season), more parameters were observed from the M-K test results to have significant trends in their variations.

The most significant trends were the AP variation (p-value $<0.001)$ and the MT (p-value $<0.01)$. These trends were found to be all increasing together with RH, DPT, VP, the $T_{L}$ and refractivity (p-values $<0.05$ ), and all with 
positive Kendall Z-values. Only the minimum temperature variation was decreasing over the years during this season, without significance ( $\mathrm{p}$-value $>0.05$ ).

Other parameters like the AT, SH, SVP, SMR, MR, PT, and EPT were increasing (positive Z-values) but without significance at a $95 \%$ confidence level.

The increasing and significant refractivity trends, the $T_{L}$, VP and DPT show that these parameters are mostly affected by the dry season. Observations reveal that the monthly variation parameters (mentioned above) have their maximum values in a month of the dry season (almost always February).

[Table 4 about here.]

[Table 5 about here.]
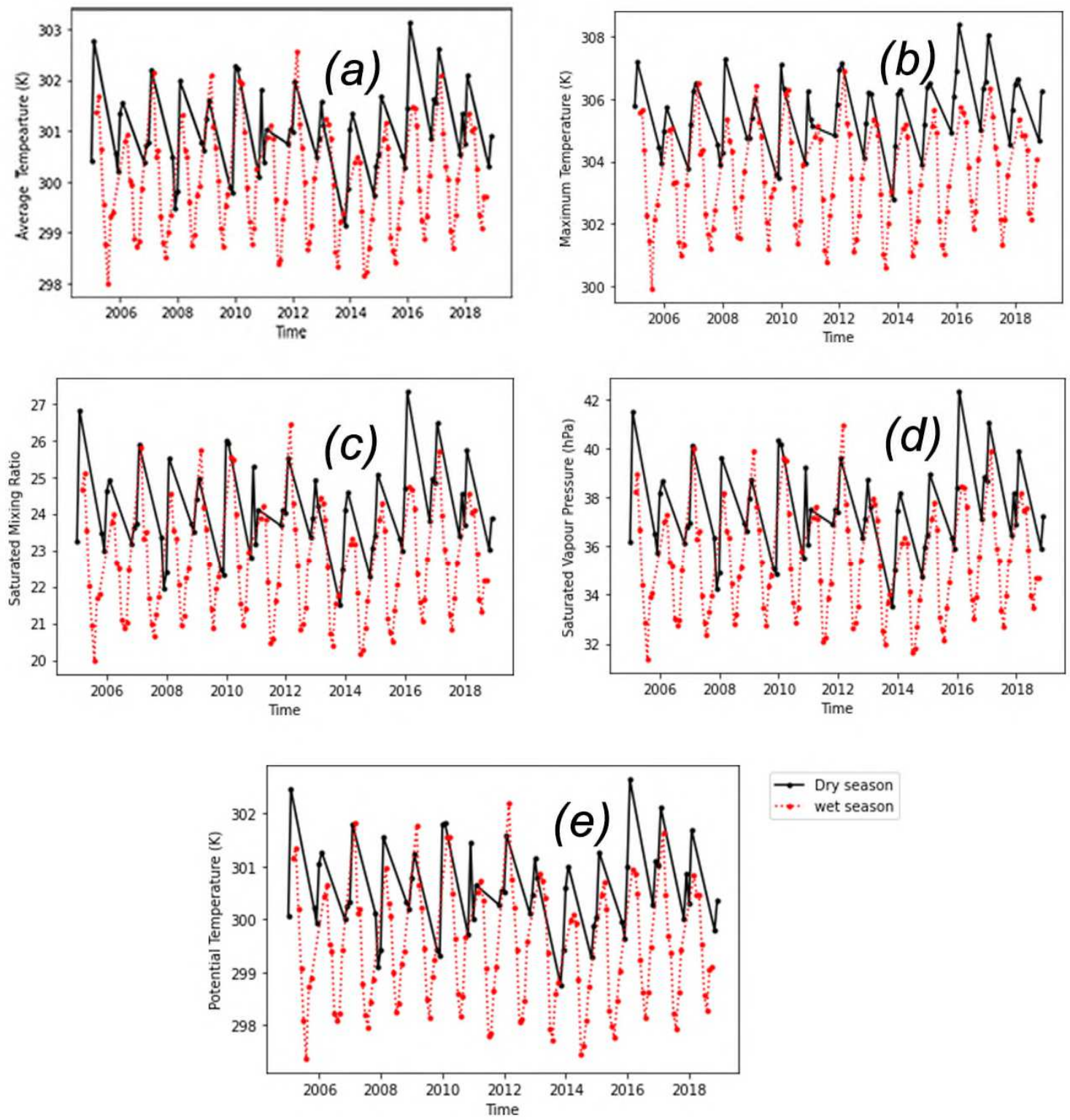

FIGURE 7: Monthly time-series variation for (a) average temperature (b) maximum temperature (c) saturated mixing ratio (d) saturated vapour pressure and (e) potential temperature, over the two seasons for the period 2005 - 2018 

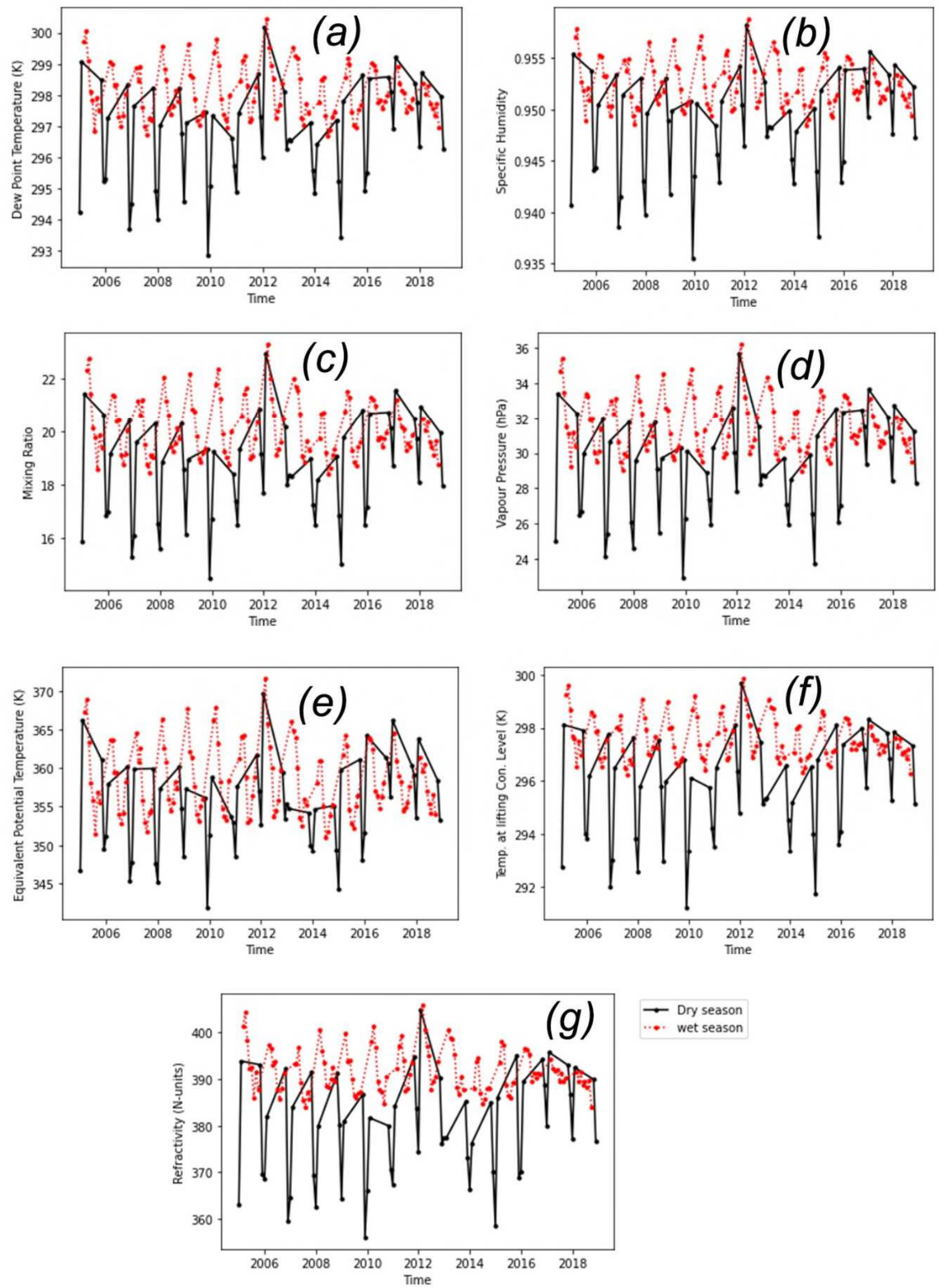

FIGURE 8: Monthly time-series variation for (a) dew point temperature (b) specific humidity (c) mixing ratio (d) vapour pressure and (e) equivalent potential temperature (f) absolute temperature at the lifting condensation level, and (g) refractivity, over the two seasons for the period $2005-2018$ 


\subsection{Discussion}

The RH trend in the dry and wet season for all years has been plotted in Figure 3. From a mere observation of the trend, it is clear that it does not show a significant increase over the years. This proves the annual, wet, and dry season M-K test results for RH (Table 1, Table 2, and table 3, respectively; negative Kendall Z values). The lowest points of the trend variation can be observed in the first two (January and February) and the last two (November and December) months of the year; these are seen in the dry season. This proves that RH variation follows a change in seasons as there is more water vapor in the atmosphere during the wet months (March through October), with the peak values observed around August (table 4). This is so for all years observed in Figure 3.

The wet months' deviation is not as much as that of the dry months, proving the region's almost uniform weather condition (Agbo et al. 2020). Results also show from the M-K test that the RH trend is increasing significantly for the dry season; this can be discerned from figure 3 as the dry season trend is growing across all years, unlike that of the wet season trend, which is higher than the dry season trend but is relatively stable compared to the dry season trend.

Observations of the AP variation in figure 4 clearly show an increasing trend over the years for both the dry and the wet seasons. This is proven by the significantly increasing trend results for the $\mathrm{M}-\mathrm{K}$ test for the annual $(\mathrm{Z}=3.83$; p-value $<0.05)$, wet season $(Z=7.79$; p-value $<0.05)$ and dry season variations $(Z=4.51$; $p$-value $<0.05)$ in table 1, table 2 and table 3 respectively. The trend has its highest points around the same time as that of RH because of the increase in the atmosphere's water vapor contents

Figure 5 shows the variation of the minimum temperature, while Figure 6 shows the variation of all the temperature trends in a single plot. We can see that the MT has a higher deviation than the minimum temperature for annual and monthly variations (table 4 and 5 shows this). This indicates that the AT is mostly affected by the MT variation. Careful observation of Figure 7 ( $a$ and $b$ ), shows that the MT and AT follows the same trend. Both were observed to have the highest values in the early months of the year (February on average) during the dry season. They steadily become lower during the heavily humid (wet season) months (June, July, and August). This shows a trend that is relatively opposite to that of $\mathrm{RH}$ in figure 3.

The SMR, the SVP, and PT trends all follow the same variation. This can be observed from the plots in figure 7 (c, d, and e). The figures are characterized by higher values in the dry season months of the year and dropping steeply during the wet season months and then climbing up steadily during the latter parts of the year towards the dry season. The trend is not significant from the observation for all years as observed from the M-K results in table 1, table 2, and table 3 for the annual, wet, and dry season variations. To prove the similarity in the trends mentioned above, we observe results from the correlation matrix for annual variation in figure 9 . We can see that these parameters all have a high positive correlation, proving our observation from the figures. The SVP and PT both have a relationship with the AT from equations (5) and (10); this is why they have a high positive correlation coefficient. These trends show an opposite variation to that of $\mathrm{RH}$; this means they don't have high values in the wet seasons, as explained earlier.

A careful observation of the variations for the DPT, SH, VP, MR, the $T_{L}$, somewhat the EPT, and refractivity trendsin Figure 8 all showed similar trends. They all have their lowest values in the dry months, and their highest values come at about the start of the wet season. It gets relatively stable for the rest of the wet months. They have the increasing variations in the dry months from the M-K test (table 3), after results show that all were increasing trends characterized by an increase in their minimum values, which is always observed in the dry months over the years. These trends were reducing as their maximum values for the wet months, were consistently observed in the wet months (evident from the figures), reduced overtime. The correlation matrix for the annual variation (figure 9) proves this from the highly positive coefficient of correlation shown between all the parameters mentioned above. 


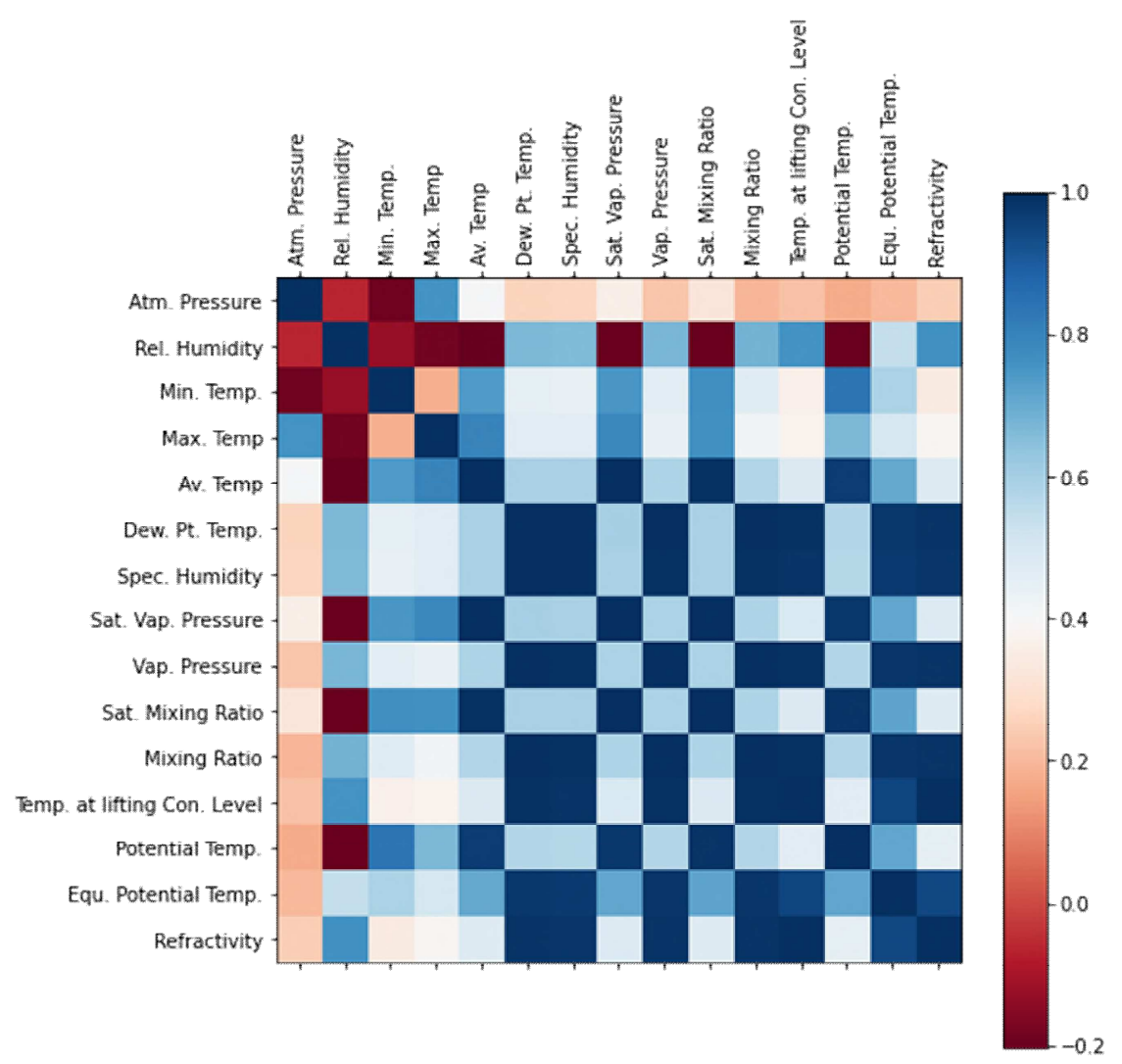

FIGURE 9: Correlation Matrix for Annual variation

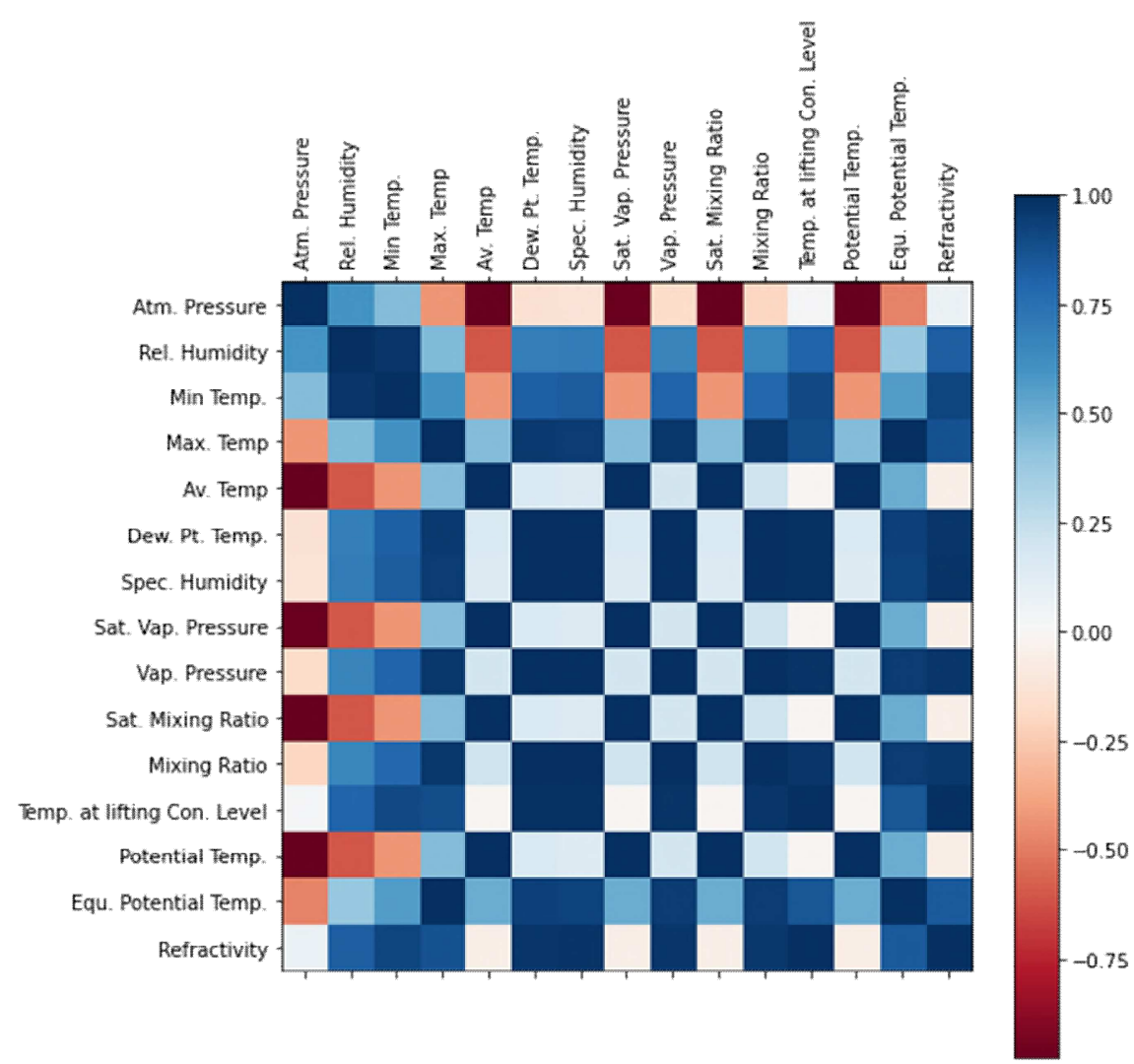

FIGURE 10: Correlation Matrix for Monthly Variation in a year 


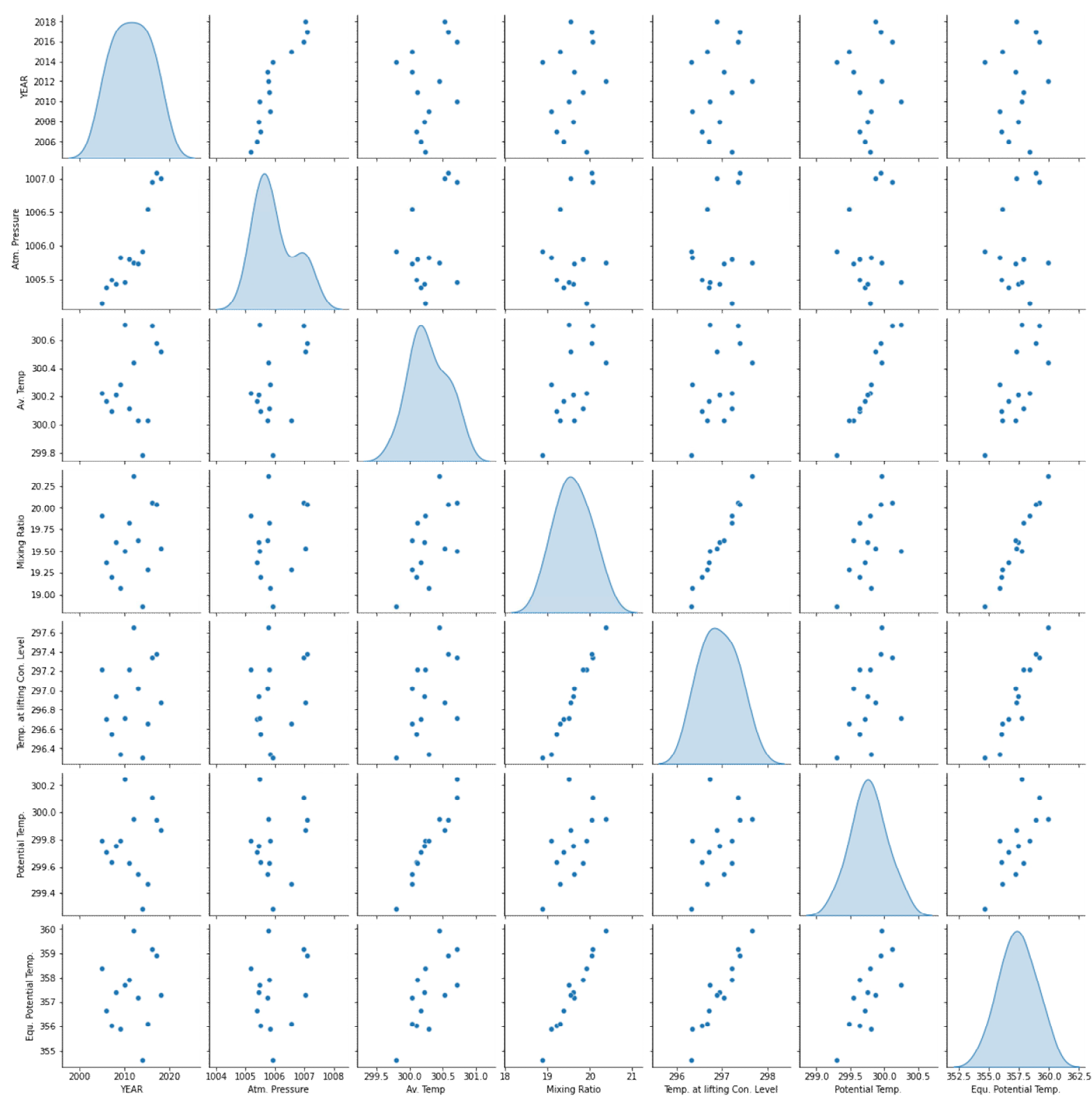

FIGURE 11: Linear regression pair plot for all parameters related to EPT, showing the nature of their relationship/dependence. 


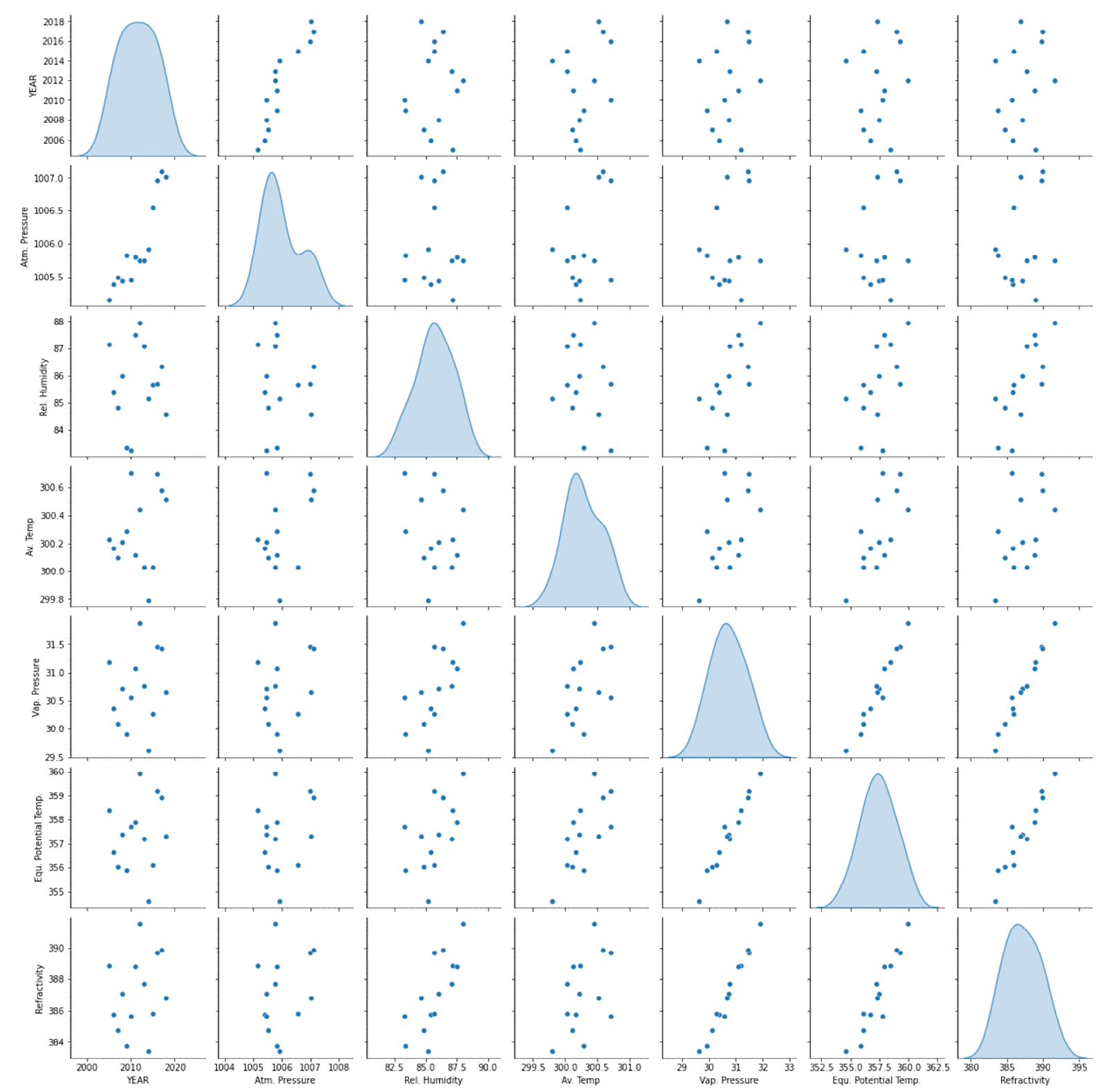

FIGURE 12: Linear regression pair plot for all parameters related to refractivity showing the nature of their relationship/dependence. 


\subsection{Annual Relationship of Parameters (Regression pair plots and Correlation Matrix)}

We aim to understand our meteorological analysis by discerning the relationships between each parameter (obtained or calculated) using regression analysis and correlation. We can see from the correlation matrix for the annual variation (figure 9) that the AT, SVP, SMR, and PT have a strong positive relationship with each other. The regression plot in figure 11 shows a strong linear relationship between AT and PT $(\mathrm{R}=0.97)$. This indicates that the AT is the same as when an unsaturated air parcel would rack up if it were adiabatically taken dry to 1000hpa (Agbo et al. 2020). We note that the SVP and the SMR are affected by the AT. The SVP deals with the pressure exerted by a vapor when it is entirely saturated, positively influenced by the ambient temperature. The same could be said for the saturated mixing ratio as this function is thermodynamic, relating to the value of the mixing ratio of saturated air, which is, of course, at a given temperature.

The relationship between the DPT, $\mathrm{SH}, \mathrm{VP}, \mathrm{MR}$, the $T_{L}$, refractivity, and the EPT are all positively correlated (figure 9) with the annual variation.

For parameters adopted for calculating the EPT, a linear regression plot is obtained in figure 9. Results show that amongst all the parameters adopted in calculating the EPT (equation 11), the AP has the least effect on the EPT's variation $(\mathrm{R}=0.20)$. The MR and temperature at the lifting condensation level $\left(T_{L}\right)$ have the most impact on her variation ( $\mathrm{R}=0.98$, and $\mathrm{R}=0.95$, respectively); this is seen in the regression plot (figure 11). The AT and PT both have a reasonably strong trend with $(\mathrm{R}=0.70)$. This trend can be explained by the fact that the $T_{L}$ and MR are both enormous contributors for EPT because the process is pseudo-adiabatic (occurring without loss or gain of heat) and involving condensation of air with respect to the dry air mass; this proves physically, the strong relationship between EPT and $T_{L}$.

For parameters adopted for calculating refractivity, the VP was found to have the most effect on the annual variation of refractivity from the regression plot (figure 12). The correlation matrix (figure 9) shows a very strong positive correlation $(\mathrm{R}=0.99)$; this proves that the refraction of radio waves which causes bending, ducting, etc. (Chinelo and Chukwumenke 2016), are massively affected by the water vapor content of the atmosphere. This can be similarly discerned from the linear regression of RH with refractivity $(\mathrm{R}=0.76)$. This result is in agreement with (Agbo et al. 2020). The atmospheric pressure has the least effect $(\mathrm{R}=0.25)$, and the average ambient temperature has a relatively strong positive coefficient of correlation $(R=0.48)$. The VP is affected by the AT and the RH; this affects most of the refractivity variation, agreeing with earlier results of the relationship between meteorological parameters and refractivity.

Finally, it is crucial to bolster the point that although an equation does not relate the refractivity and the EPT, they have a very similar trend variation. The linear regression of the annual trend seen in figure 12 proves this close positive relationship, confirmed by a high positive correlation coefficient in figure 12 ( $\mathrm{R}=0.95)$. This result is seen because both EPT and refractivity have to do with water vapor parameters in the atmosphere (condensation and vapor pressure, respectively).

\subsection{Monthly Relationship of Parameters (Regression pair plots and Correlation Matrix)}

The variation of the studied parameters with each other has also been analyzed for months in a year. The relationship between them has been displayed in the correlation matrix in Figure 10.

The results show some similarities with that of the correlation for the annual variation. The difference here is that the measured meteorological parameters (AP, RH, minimum, temperature, and MT) show more effects (negative or positive) on the calculated parameters.

The AP, for example, showed a strong negative coefficient of correlation with AT, SVP, SMR, and PT. This result shows that for the monthly variation in a year, this effect was not observed in the annual variation (figure 9); the AP has an inverse relationship with these mentioned parameters for the monthly variation. Results show little or no dependence of monthly refractivity variation with AP. $(R=0.07)$; this was in huge contrast to $\mathrm{RH}$ and refractivity for the monthly trends after showing a strong positive correlation $(\mathrm{R}=0.83)$.

$\mathrm{RH}$ is similarly positively correlated with the $T_{L}(\mathrm{R}=0.80)$ and $\mathrm{SH}(\mathrm{R}=0.70)$.

One thing to note about the effects of the AT on some parameters is that the SVP, SMR, and the PT all have an almost perfect correlation with the trend of AT for months in a year. This interpretation happens to be approximately similar to that of the annual correlation between them. It shows that the relationship between their variation is not affected by the change in seasons during the year.

We note again that for monthly refractivity, the correlation coefficient is high for all parameters relating to the water vapor contents of the atmosphere (RH, DPT, SH, VP, MR, $T_{L}$ and the EPT) observed from Figure 10. The same could be said for the variation of EPT.

To further understand the relationship/contribution the related parameters have on the EPT, we obtain partial differentials of equation (11) with respect to the meteorological parameters contributing to its variation while 
keeping other parameters constant. We do this to find the magnitude of their respective gradients; We obtain the partial derivative of EPT with respect to the AT as;

$$
\frac{\partial \theta_{E}}{\partial T_{K}}=1000^{0.2854\left(1-0.28 \times 10^{-3} r\right)} \times \exp \left[\left(1+0.81 \times 10^{-3} r\right) r\left(\frac{3.376}{T_{L}}-0.00254\right)\right]\left(\frac{1}{P}\right)^{0.2854\left(1-0.28 \times 10^{-3} r\right)}
$$

Similarly, we obtain the derivative of EPT with respect to the $T_{L}$;

$$
\frac{\partial \theta_{E}}{\partial T_{L}}=\frac{3.376 \times 1000^{0.2854\left(1-0.28 \times 10^{-3} r\right)} \times \exp \left[\left(1+0.81 \times 10^{-3} r\right) r\left(\frac{3.376}{T_{L}}-0.00254\right)\right]\left(\frac{1}{P}\right)^{0.2854\left(1-0.28 \times 10^{-3} r\right)}\left(1+0.81 \times 10^{-3} r\right) r T_{K}}{T_{L}^{2}}
$$

The derivative of EPT with respect to the MR of the water vapor is;

$$
\begin{aligned}
& \frac{\partial \theta_{E}}{\partial r}=-0.0005520131000^{0.2854\left(1-0.28 \times 10^{-3} r\right)} \times \exp \left[\left(1+0.81 \times 10^{-3} r\right) r\left(\frac{3.376}{T_{L}}-0.00254\right)\right]\left(\frac{1}{P}\right)^{0.2854\left(1-0.28 \times 10^{-3} r\right)} T_{K} \\
& +1000^{0.2854\left(1-0.28 \times 10^{-3} r\right)} \times \exp \left[\left(1+0.81 \times 10^{-3} r\right) r\left(\frac{3.376}{T_{L}}-0.00254\right)\right]\left(\frac{1}{P}\right)^{0.2854\left(1-0.28 \times 10^{-3} r\right)} \\
& \times T_{K}\left[\left(1+0.81 \times 10^{-3} r\right)\left(\frac{3.376}{T_{L}}-0.00254\right)+0.81 \times 10^{-3} r\left(\frac{3.376}{T_{L}}-0.00254\right)\right] \\
& -0.000079912 \times 1000^{0.2854\left(1-0.28 \times 10^{-3} r\right)} \times \exp \left[\left(1+0.81 \times 10^{-3} r\right) r\left(\frac{3.376}{T_{L}}-0.00254\right)\right]\left(\frac{1}{P}\right)^{0.2854\left(1-0.28 \times 10^{-3} r\right)} T_{K} \log \left(\frac{1}{P}\right)
\end{aligned}
$$

For the AP, this brings;

$\frac{\partial \theta_{E}}{\partial P}=-0.2854 \times 1000^{0.2854\left(1-0.28 \times 10^{-3} r\right)} \times \exp \left[\left(1+0.81 \times 10^{-3} r\right) r\left(\frac{3.376}{T_{L}}-0.00254\right)\right]\left(\frac{1}{P}\right)^{1+0.2854\left(1-0.28 \times 10^{-3} r\right)}\left(1-0.28 \times 10^{-3} r\right) T_{K}$

And finally, we obtain the partial derivative of EPT with respect to PT

$$
\frac{\partial \theta_{E}}{\partial \theta}=\exp \left[\left(1+0.81 \times 10^{-3} r\right) r\left(\frac{3.376}{T_{L}}-0.00254\right)\right]
$$

Now we analyze with the total annual values of the parameters, by substituting the values for $T_{K}=300.28, P=1005.97, r=19.59, T_{L}=296.92$ into equations (19), (20), (21), (22), (23) we get;

$\frac{\partial \theta_{E}}{\partial T_{K}}=1.1901$

$\frac{\partial \theta_{E}}{\partial T_{L}}=-0.272336$

$\frac{\partial \theta_{E}}{\partial r}=3.25585$

$\frac{\partial \theta_{E}}{\partial P}=-0.10083$

$\frac{\partial \theta_{E}}{\partial \theta}=1.19211$

The above results agree majorly with our correlation results from figure 9. The results from figure 9 shows that the MR has the highest coefficient of correlation with EPT; this corresponds to the highest gradient from equation (25), this is followed by the PT, the AT, and the AP. However, an anomaly was observed in the gradient of EPT with $T_{L}$ as it did not agree with the strong positive correlation coefficient from Figure 9. This result may be attributed to the fact that the variation $T_{L}$ has little or no effect on EPT variation, but their trends are similar, as explained by the correlation results. 


\section{Conclusion}

The relationship between some meteorological parameters relating to the variations of radio refractivity (RH, AP, AT, SVP, VP), parameters relating to the EPT (PT, $T_{L}$, MR, SMR) as well as the DPT and SH were all analyzed to show their effects and to discern the relationship they all have with each other. Their trends were analyzed using the $\mathrm{M}-\mathrm{K}$ trend test for annual and seasonal variations.

Data were obtained for the minimum temperature and MT, AP, and RH for 14 years (2005-2018). Values for other parameters were calculated and applied.

The correlation matrixes and linear regression pair plots show a strong relationship between the variations of refractivity, EPT, $T_{L}, \mathrm{MR}, \mathrm{VP}, \mathrm{SH}$, and DPT. The PT, SVP, SMR, and AT relationship showed a very strong positive correlation/regression. This offers a connection between the AT and the PT, proving that the AT is almost equal to the temperature which an unsaturated air parcel would rack up if lifted dry adiabatically to $1000 \mathrm{hPa}$; this is related to the SVP and SMR.

The M-K test was applied annually (using the M-K original test) and the dry and wet seasons (using the seasonal M-K test). Adopting four months (November through February) for the dry season and eight months (March through October) for the wet season, obtained and calculated data were tested to infer trends with results showing that despite the increasing and decreasing variations of some parameters, some of their trends were not increasing or decreasing with significance after their $p$-values were found to less than the highest acceptable level of significance adopted in this study $(\alpha=0.05)$.

Results from the M-K test show that the AP and the MT were both increasing significantly for both the annual and seasonal (dry and wet) variations after they were both found to have p-values $<0.05$ for all variations. Other parameters which were increasing significantly were the $\mathrm{RH}$ and the minimum temperature (during the dry season). Consequently, in addition to the AP and maximum temperature, the RH, DPT, T(L), and refractivity were all increasing significantly (although at different significant levels) during the wet season; these parameters are directly or indirectly related to the water vapor component atmosphere.

To crystalize our results on the relationship between some parameters related by equations, we have adopted a novel technique of partially differentiating the equation for EPT, obtaining partial derivatives of the EPT ( $\left.\theta_{E}\right)$ with respect to parameters relating to its variation from equation (11). The gradients of these partials derivatives were presented in equations (equation). Data were used to obtain the magnitude of these derivatives' gradients to show how its results agree with the correlation matrix and linear regression pair plots.

Results from the magnitude of this gradient show that the MR of air variations has the most significant effect on the EPT variation for a pseudo-adiabatic process from equation (24).

In general, our results give a detailed understanding of all these parameters' trends and, most importantly, their relationships with each other. The results obtained here will provide readers and fellow researchers with an idea of how meteorological parameters affects each other's change and trend, giving a general idea on meteorological analysis.

An understanding of the variation of moist air potential temperature can, and has been applied by Marquet (2011) FIRE-I data flights, this shows the vast appliavtions of these results. These results can be applied to other regions for meteorological forecasting and modeling as a panacea to an ever-changing climatic problem. Similarly, results can be applied to regions with the same climatic conditions (same latitude) to understand the kinds of devices (e.gs are devices for energy consumption) that are dependent on meteorological variability, as elaborated by Liu et al. (2017). 


\section{Conflict of Interest}

The authors declare no conflict of interest.

\section{Funding Statement}

This study was self-sponsored, and the authors received no funding

\section{Author's Contribution}

Emmanuel P. Agbo designed the study, handled the review, acquired and analyzed, and interpreted the data; Collins O Edet interpreted the data also and revised the article critically for important intellectual content. Both authors gave their approval to the final manuscript after reading it.

\section{Data Availability}

Data was obtained from the Nigeran Meteorological Agency (NiMet) and will be made available on request

\section{Code Availability}

The link to the codes for the study will be made available on request

\section{Ethics Approval}

The authors declare that all procedures performed during the study, etc are in accordance with the COPE (Committee on Publication Ethics) guidelines ethical standards. Authors also declare that the study procedures did not involve human and animal participations.

\section{Consent to Participate}

The study did not involve any human participation, data was obtained and analyzed; hence consent to participate wasn't necessary

\section{Consent for Publication}

Authors have granted the publisher the right to publish the study. Simultaneoulsy, consent for publication was not neccasary because the study did not involve any human participation.

\section{REFERENCES}

Adediji AT, Ajewole MO, Falodun SE (2011) Distribution of radio refractivity gradient and effective earth radius factor (k-factor) over Akure, South, Western Nigeria. Journal of Atmospheric and Solar Terrestrial Physics. 73:2300 - 2304. https://doi.org/10.1016/j.jastp.2011.06.017

Adediji AT, Ismail M, Mandeep JS (2014). Performance analysis of microwave radio refractivity on radio field strength and radio horizon distance over Akure, Nigeria. Wireless Pers Commun 79:1893-1909. https://doi.org/10.1007/s11277-014-1963-0

Agbo EP (2021). The role of statistical methods and tools for weather forecasting and modeling [Online First]. In Weather Forecassting. IntechOpen, https://doi.org/10.5772/intechopen.96854.

Agbo EP, Edet, CO Magu TO, Njok AO, Ekpo CM, \& Louis H. (2021a). Solar energy: A panacea for the electricity generation crisis in Nigeria. Heliyon, 7(5), e07016.https://doi.org/10.1016/j.heliyon.2021.e07016

Agbo EP, Ekpo CM, Edet CO (2021b). Analysis of the effects of meteorological parameters on radio refractivity, equivalent potential temperature and field strength via Mann-Kendall test. Theor Appl Climatol. https://doi.org/10.1007/s00704-020-03464-1

Agbo EP, Ekpo CM. (2021, January) Trend Analysis of the Variations of Ambient Temperature Using Mann-Kendall Test and Sen's Estimate in Calabar, Southern Nigeria. In Journal of Physics: Conference Series (Vol. 1734, No. 1, p.012016). IOP Publishing. DOI: https://doi.org/10.1088/1742-6596/1734/1/012016

Agbo EP, Ekpo CM. (2020) Trend Analysis of the Variations of Ambient Temperature Using MannKendall Test and Sen's Estimate in Calabar, Southern Nigeria. Researchgate Preprint DOI: https://doi.org/10.13140/RG.2.2.26163.04644

Agbo EP, Ettah EB, Eno EE (2020) The impacts of meteorological parameters on the seasonal, monthly and annual variation of radio refractivity. Indian J Phys. https://doi.org/10.1007/s12648-020-01711-9 
Agbo GA, Okoro ON, Amechi AO (2013) Atmospheric refractivity over Abuja, Nigeria. International Research Journal of Pure and Applied Physics, 1: 37 - 45 www.ea-journals.org

Akpinar S, Oztop, HF and Akpinar EK (2008) Evaluation of relationship between meteorological parameters and air pollutant concentrations during winter season in Elazığg, Turkey. Environmental monitoring and assessment, 146(1), 211-224.

Alhaji UU, Yusuf AS, Edet CO, Oche CO, Agbo E P (2018) Trend analysis of temperature in Gombe state using Mann Kendall Trend test. Journal of Scientific Research and Reports 20(1): 1-9 https://doi.org/10.9734/JSRR/2018/42029

Atta-ur-Rahman, Dawood M (2017) Spatio-statistical analysis of temperature fluctuation using MannKendall and Sen's slope approach. Clim Dyn (48):783-797. https://doi.org/10.1007/s00382-016-3110-y

Ayantunji BG, Okeke PN, Urana JO (2011) Diurnal and seasonal variation of surface refractivity over Nigeria. Progress in Electromagnetics Research B. 30: 201 - 222

Bolton D (1980) The computation of equivalent potential temperature. Monthly Weather Review. 108: 1046 - $\quad 1053 \quad$ http://journals.ametsoc.org/mwr/article-pdf/108/7/1046/4166788/15200493(1980)108 1046 tcoept_2_0_co_2.

Bechtold P. (2009) Atmospheric thermodynamics. ECMWF Lecture Notes. 22.

Bryan GH (2008) On the computation of pseudoadiabatic entropy and equivalent potential temperature. Notes and Correspondence. 131: 5239 - 5245 https://doi.org/10.1175/2008MWR2593.1

Chattopadhyay G, Chakraborthy P, and Chattopadhyay S (2012) Mann-Kendall trend analysis of tropospheric ozone and its modeling using ARIMA. Theor Appl Climatol (110): 321-328. https://doi.org/10.1007/s00704-012-0617-y.

Chukwunike OC, Chinelo IU (2016) The investigation of vertical surface radio refractivity gradient in Akwa, south eastern Nigeria. International Journal of Academic Research and Reflection. 4(6):28 - 36

Dairo OF, Kolawole LB (2017) Statistical analysis of radio refractivity gradient of the rainy harmattan transition phase of the lowest 100m over Lagos, Nigeria. Journal of Atmospheric and Solar Physics.

Davies-Jones R. (2009) On formulas for equivalent potential temperature. Monthly weather review. 137(9):3137-48.

Falodun SE, Okeke PN (2013) Radiowave propagation measurements in Nigeria (preliminary reports). Theor Appl Climatol 113: 127-135. https://doi.org/10.1007/s00704-012-0766-Z

Fang GC, Wu YS, Wen CC, Lee WJ, and Chang SY (2007) Influence of meteorological parameters on particulates and atmospheric pollutants at Taichung harbor sampling site. Environmental monitoring and assessment, 128(1), 259-275.

Gao S, Cao J. (2007) Physical basis of generalized potential temperature and its application to cyclone tracks in nonuniformly saturated atmosphere. Journal of Geophysical Research: Atmospheres. 27;112(D18)

Grinn-Gofron, A and Bosiacka B (2015) Effects of meteorological factors on the composition of selected fungal spores in the air. Aerobiologia, 31(1), 63-72.

Grinn-Gofron A and Strzelczak A (2011) The effects of meteorological factors on the occurrence of Ganoderma sp. spores in the air. International Journal of Biometeorology, 55(2), 235-241.

Heimann D. (1992) Potential and equivalent-potential temperature patterns at cold fronts with prefrontal foehn. Meteorology and Atmospheric Physics. 48(1):165-71. https://doi.org/10.1007/BF01029565

Javeed S, Alimgeer KS, Javeed W, Atif M, Uddin, M (2018) A modified artificial neural network based prediction technique for tropospheric radio refractivity. PLos ONE 13(3): e0192069. https://doi.org/10.1371/journal.pone.0192069.

Kaissassou S, Lenouo A, Tchawoua C, Lopez P, Gaye AT (2015) `Climatology of radar anomalous propagation over West Africa. Journal of Atmospheric and Solar Terrestrial Physics 123:1-12 http://dx.doi.org/10.1016/j.jastp.2014.11.009

Kim J, Kim Y, Lee J, Choi Y (2014) Analysis of pathloss characteristics with variation of refractivity gradient using the parabolic equation. Electronics and Telecommunications Research Institute. https://www.researchgate.net/publication/260318838

Kisi O, Ay M (2014) Comparison of Mann-Kendall and innovative trend method for water quality parameters of the Kizilirmak River, Turkey. Journal of Hydrology 513:362-375 http://dx.doi.org/10.1016/j.jhydrol.2014.03.005

Liu D, Wang W and Liu J (2017) Sensitivity analysis of meteorological parameters on building energy consumption. Energy Procedia, 132, 634-639.

Marquet P. (2011) Definition of a moist entropy potential temperature: application to FIRE-I data flights. Quarterly Journal of the Royal Meteorological Society. 137(656):768-91. https://doi.org/10.1002/qj.787

Mondal A, Kundu S, Mukhopadhyay A (2012) Rainfall trend analysis by Mann-Kendall test: a case study of north-eastern part of Cuttack district, Oriss. International Journal of Geology, Earth and Environmental Sciences. 2(1): 70 - 78 http://www.cibtech.org/jgee.htm

Ogunsua BO, Ojo JS, Adediji AT (2018) Atmospheric chaoticity and complexity from radio refractivity derived from Akure station. Advances in Space Research. https://doi.org/10.1016/j.asr.2018.06.035 
Ojo OS, Adeyemi WA, Abioye IO (2015) Variation of surface refractivity with air temperature over savannah and coastal zones in Nigeria. Proceedings of National Conference on Engineering and Technology, Osun State, Nigeria. 1:144 - 147

Oyedum OD (2008) Climatic and seasonal variations of effective-earth-radius factor and scale height in three meteorological stations in West Africa. Nigerian Journal of Physics 20(1):102 - 111

Salmi T, Määttä A, Anttila P, Ruoho-Airola T, Amnell T (2002) Detecting trends of annual values of atmospheric pollutants by the Mann-Kendall test and Sen's slope estimates; the excel template application Makesens. Finnish Meteorological Institute Vuorikatu 24, P.O. Box 503 FIN-00101 Helsinki, Finland. Publications on Air Quality 31.

Sen PK (1968) Estimates of the regression coefficient based on Kendall's tau. Journal of the American Statistical Association 63:1379-1389 http://links.jstor.org/sici?sici=01621459\%28196812\%2963\%3A324\%3C1379\%3AEOTRCB\%3E2.0.CO\%3B2-A

Zhou Y, Liu L, Deng G. (2009) Comparisons of the generalized potential temperature in moist atmosphere with the equivalent potential temperature in saturated moist atmosphere. Advances in Meteorology.

\section{List of Tables}

1. Table 1: Results of the M-K trend test for each parameter showing the nature of each of their annual variation.

2. Table 2: Results of the M-K trend test for each parameter showing the nature of each of their variation in the wet (rainy) season.

3. Table 3: Results of the M-K trend test for each parameter showing the nature of each of their variation in the dry season.

4. Table 4: Descriptive statistics for annual variation showing the mean, standard deviation (std), and the 5point summary (minimum, different quartile values, and the maximum). Where $25 \%, 50 \%, 75 \%$ are the $1^{\text {st }}$ quartile (Q1), $2^{\text {nd }}$ quartile $(\mathrm{Q} 2)$, and $3^{\text {rd }}$ quartile (Q3) values, respectively.-

5. Table 5: Descriptive statistics for monthly variation showing the mean, standard deviation (std), and the 5 -point summary (minimum, different quartile values, and the maximum). Where $25 \%, 50 \%, 75 \%$ are the $1^{\text {st }}$ quartile $(\mathrm{Q} 1), 2^{\text {nd }}$ quartile $(\mathrm{Q} 2)$, and $3^{\text {rd }}$ quartile $(\mathrm{Q} 3)$ values, respectively. 
TABLE 1

Results of the M-K trend test for each parameter, showing the nature of each of their annual variation.

\begin{tabular}{|c|c|c|c|c|c|c|c|c|c|}
\hline Variables & $\begin{array}{c}\text { Kendall's } \\
\text { Tau }\end{array}$ & $\begin{array}{c}\text { Mann } \\
\text { Kendall's } \\
\text { Statistic } \\
(\mathbf{S}) \\
\end{array}$ & $\operatorname{VAR}(\mathbf{S})$ & $\begin{array}{c}\text { Test } \\
\text { Statistic } \\
(\mathrm{Z})\end{array}$ & $\begin{array}{c}\text { p-value } \\
\text { (Two- } \\
\text { tailed) }\end{array}$ & Intercept & $\begin{array}{l}\text { Sen's } \\
\text { slope } \\
(\mathrm{Q})\end{array}$ & $\begin{array}{c}\text { Test } \\
\text { Interpretation }\end{array}$ & trend \\
\hline $\mathrm{AP}$ & 0.78 & 71.00 & 333.67 & 3.83 & 0.00013 & 1004.86 & 0.14 & TRUE*** & $\mathrm{SF}(\uparrow)$ \\
\hline RH & -0.03 & -3.00 & 333.67 & -0.11 & 0.91 & 85.83 & -0.02 & FALSE & $\operatorname{NSF}(\downarrow)$ \\
\hline Min Temp. & -0.23 & -21.00 & 333.67 & -1.09 & 0.27 & 296.62 & -0.02 & FALSE & $\operatorname{NSF}(\downarrow)$ \\
\hline MT & 0.52 & 47.00 & 333.67 & 2.52 & 0.01 & 303.52 & 0.07 & TRUE* & $\mathrm{SF}(\uparrow)$ \\
\hline AT & 0.08 & 7.00 & 333.67 & 0.33 & 0.74 & 300.07 & 0.02 & FALSE & $\operatorname{NSF}(\uparrow)$ \\
\hline DPT & 0.12 & 11.00 & 333.67 & 0.55 & 0.58 & 297.49 & 0.02 & FALSE & $\operatorname{NSF}(\uparrow)$ \\
\hline SH & 0.19 & 17.00 & 333.67 & 0.88 & 0.38 & 0.95 & 0.00006 & FALSE & $\operatorname{NSF}(\uparrow)$ \\
\hline SVP & 0.08 & 7.00 & 333.67 & 0.33 & 0.74 & 35.60 & 0.03 & FALSE & $\operatorname{NSF}(\uparrow)$ \\
\hline VP & 0.12 & 11.00 & 333.67 & 0.55 & 0.58 & 30.52 & 0.03 & FALSE & $\operatorname{NSF}(\uparrow)$ \\
\hline SMR & 0.03 & 3.00 & 333.67 & 0.11 & 0.91 & 22.86 & 0.02 & FALSE & $\operatorname{NSF}(\uparrow)$ \\
\hline MT & 0.12 & 11.00 & 333.67 & 0.55 & 0.58 & 19.48 & 0.01 & FALSE & $\operatorname{NSF}(\uparrow)$ \\
\hline$T_{L}$ & 0.16 & 15.00 & 333.67 & 0.77 & 0.44 & 296.78 & 0.02 & FALSE & $\operatorname{NSF}(\uparrow)$ \\
\hline PT & 0.01 & 1.00 & 333.67 & 0.00 & 1.00 & 299.76 & 0.001 & FALSE & $\operatorname{NSF}(\uparrow)$ \\
\hline EPT & 0.10 & 9.00 & 333.67 & 0.44 & 0.66 & 357.00 & 0.05 & FALSE & $\operatorname{NSF}(\uparrow)$ \\
\hline Refractivity & 0.16 & 15.00 & 333.67 & 0.77 & 0.44 & 385.98 & 0.15 & FALSE & $\operatorname{NSF}(\uparrow)$ \\
\hline
\end{tabular}

*Trend present at $5 \%(0.05)$ level of significance i.e., (p-value $<0.05)$

$* * *$ Trend present at $0.1 \%(0.001)$ level of significance i.e., (p-value $<0.001$ )

$(\uparrow)$ indicates an increasing variation and $(\downarrow)$ indicates a decreasing variation

$\mathrm{NSF}$ - no significant trend

$\mathrm{SF}$ - significant trend 
TABLE 2

Results of the M-K trend test for each parameter, showing the nature of each of their variation in the wet (rainy) season.

\begin{tabular}{lrrrrrrrrl}
\hline Variables & $\begin{array}{c}\text { Kendall's } \\
\text { Tau }\end{array}$ & $\begin{array}{c}\text { Mann } \\
\text { Kendall's } \\
\text { Statistic } \\
(\mathbf{S})\end{array}$ & VAR(S) & $\begin{array}{c}\text { Test } \\
\text { Statistic } \\
(\mathbf{Z})\end{array}$ & $\begin{array}{c}\text { p-value } \\
\text { (Two- } \\
\text { tailed) }\end{array}$ & Intercept & $\begin{array}{c}\text { Sen's } \\
\text { slope } \\
(\mathbf{Q})\end{array}$ & $\begin{array}{c}\text { Test } \\
\text { Interpretation }\end{array}$ & trend \\
\hline AP & 0.55 & \multicolumn{1}{c}{400.00} & 2624.00 & 7.79 & $6.7 \mathrm{E}-15$ & 1005.75 & 0.14 & TRUE*** & SF $(\uparrow)$ \\
RH & -0.21 & -150.00 & 2667.33 & -2.89 & 0.004 & 90.92 & -0.13 & TRUE** & SF $(\downarrow)$ \\
Min Temp. & -0.16 & -119.00 & 2657.67 & -2.29 & 0.02 & 296.62 & -0.03 & TRUE** & SF $(\downarrow)$ \\
MT & 0.29 & 210.00 & 2663.33 & 4.05 & 0.0001 & 302.85 & 0.06 & TRUE*** & SF $(\uparrow)$ \\
AT & 0.13 & 96.00 & 2667.33 & 1.84 & 0.07 & 299.68 & 0.02 & FALSE & NSF $(\uparrow)$ \\
DPT & -0.06 & -46.00 & 2669.33 & -0.87 & 0.38 & 297.93 & -0.01 & FALSE & NSF $(\downarrow)$ \\
SH & -0.07 & -52.00 & 2669.33 & -0.99 & 0.32 & 0.95 & -0.00003 & FALSE & NSF $(\downarrow)$ \\
SVP & 0.13 & 96.00 & 2667.33 & 1.84 & 0.07 & 34.65 & 0.03 & FALSE & NSF $(\uparrow)$ \\
VP & -0.06 & -46.00 & 2669.33 & -0.87 & 0.38 & 31.22 & -0.01 & FALSE & NSF $(\downarrow)$ \\
SMR & 0.12 & 90.00 & 2669.33 & 1.72 & 0.08 & 22.20 & 0.02 & FALSE & NSF $(\uparrow)$ \\
MT & -0.07 & -52.00 & 2669.33 & -0.99 & 0.32 & 19.92 & -0.01 & FALSE & NSF $(\downarrow)$ \\
$T_{L}$ & -0.05 & -38.00 & 2669.33 & -0.72 & 0.47 & 297.46 & -0.01 & FALSE & NSF $(\downarrow)$ \\
PT & 0.03 & 24.00 & 2669.33 & 0.45 & 0.66 & 299.21 & 0.004 & FALSE & NSF $(\uparrow)$ \\
EPT & -0.05 & -36.00 & 2669.33 & -0.68 & 0.50 & 357.97 & -0.04 & FALSE & NSF $(\downarrow)$ \\
Refractivity & -0.04 & -28.00 & 2669.33 & -0.52 & 0.60 & 391.18 & -0.03 & FALSE & NSF $(\downarrow)$ \\
\hline
\end{tabular}

**Trend present at 1\%(0.01) level of significance i.e., (p-value $<0.01)$

$* * *$ Trend present at $0.1 \%(0.001)$ level of significance i.e., (p-value $<0.001)$

$(\uparrow)$ indicates an increasing variation and $(\downarrow)$ indicates a decreasing variation

$\mathrm{NSF}$ - no significant trend

$\mathrm{SF}$ - significant trend 
TABLE 3

The M-K trend test results for each parameter showing the nature of each of their variation in the dry season.

\begin{tabular}{|c|c|c|c|c|c|c|c|c|c|}
\hline Variables & $\begin{array}{c}\text { Kendall's } \\
\text { Tau }\end{array}$ & $\begin{array}{c}\text { Mann } \\
\text { Kendall's } \\
\text { Statistic } \\
\text { (S) }\end{array}$ & VAR(S) & $\begin{array}{c}\text { Test } \\
\text { Statistic } \\
(Z)\end{array}$ & $\begin{array}{c}\text { p-value } \\
\text { (Two- } \\
\text { tailed) }\end{array}$ & Intercept & $\begin{array}{c}\text { Sen's } \\
\text { slope } \\
(\mathbf{Q})\end{array}$ & $\begin{array}{c}\text { Test } \\
\text { Interpretation }\end{array}$ & trend \\
\hline $\mathrm{AP}$ & 0.45 & 165.00 & 1325.00 & 4.51 & $6.6 \mathrm{E}-06$ & 1004.14 & 0.13 & TRUE*** & $\mathrm{SF}(\uparrow)$ \\
\hline RH & 0.20 & 74.00 & 1332.67 & 2.000 & 0.046 & 75.22 & 0.19 & TRUE* & $\mathrm{SF}(\uparrow)$ \\
\hline Min Temp. & -0.14 & -52.00 & 1332.67 & -1.40 & 0.16 & 296.82 & -0.04 & FALSE & $\operatorname{NSF}(\downarrow)$ \\
\hline MT & 0.33 & 119.00 & 1333.67 & 3.23 & 0.0012 & 305.10 & 0.08 & TRUE** & $\mathrm{SF}(\uparrow)$ \\
\hline $\mathrm{AT}$ & 0.11 & 40.00 & 1334.67 & 1.07 & 0.29 & 300.73 & 0.02 & FALSE & $\operatorname{NSF}(\uparrow)$ \\
\hline DPT & 0.21 & 76.00 & 1334.67 & 2.05 & 0.04 & 296.39 & 0.08 & TRUE* & $\mathrm{SF}(\uparrow)$ \\
\hline SH & 0.19 & 70.00 & 1334.67 & 1.89 & 0.06 & 0.95 & 0.00026 & FALSE & $\operatorname{NSF}(\uparrow)$ \\
\hline SVP & 0.11 & 40.00 & 1334.67 & 1.07 & 0.29 & 36.84 & 0.04 & FALSE & $\operatorname{NSF}(\uparrow)$ \\
\hline VP & 0.21 & 76.00 & 1334.67 & 2.05 & 0.04 & 28.46 & 0.15 & TRUE* & $\mathrm{SF}(\uparrow)$ \\
\hline SMR & 0.10 & 38.00 & 1334.67 & 1.01 & 0.31 & 23.66 & 0.02 & FALSE & $\operatorname{NSF}(\uparrow)$ \\
\hline MT & 0.19 & 70.00 & 1334.67 & 1.89 & 0.06 & 18.13 & 0.09 & FALSE & $\operatorname{NSF}(\uparrow)$ \\
\hline$T_{L}$ & 0.21 & 76.00 & 1334.67 & 2.05 & 0.04 & 295.07 & 0.11 & TRUE* & $\mathrm{SF}(\uparrow)$ \\
\hline PT & 0.04 & 14.00 & 1334.67 & 0.36 & 0.72 & 300.28 & 0.009 & FALSE & $\operatorname{NSF}(\uparrow)$ \\
\hline EPT & 0.19 & 68.00 & 1334.67 & 1.83 & 0.07 & 353.62 & 0.236 & FALSE & $\operatorname{NSF}(\uparrow)$ \\
\hline Refractivity & 0.21 & 78.00 & 1334.67 & 2.11 & 0.04 & 376.14 & 0.58 & TRUE* & $\mathrm{SF}(\uparrow)$ \\
\hline
\end{tabular}

$*$ Trend present at $5 \%(0.05)$ level of significance i.e., $(\mathrm{p}$-value $<0.05)$

**Trend present at $1 \%(0.01)$ level of significance i.e., (p-value $<0.01)$

$* * *$ Trend present at $0.1 \%(0.001)$ level of significance i.e., (p-value $<0.001$ )

$(\uparrow)$ indicates an increasing variation and $(\downarrow)$ indicates a decreasing variation

$\mathrm{NSF}$ - no significant trend

$\mathrm{SF}$ - significant trend 
TABLE 4

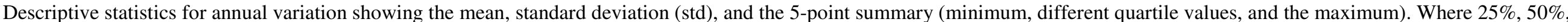
$75 \%$ are the $1^{\text {st }}$ quartile $(\mathrm{Q} 1), 2^{\text {nd }}$ quartile $(\mathrm{Q} 2)$, and $3^{\text {rd }}$ quartile $(\mathrm{Q} 3)$ values, respectively

\begin{tabular}{lrrrrrrr}
\hline Parameters & \multicolumn{1}{c}{ mean } & \multicolumn{1}{c}{ std } & \multicolumn{1}{c}{ min } & \multicolumn{1}{c}{$\mathbf{2 5 \%}$} & \multicolumn{1}{c}{$\mathbf{5 0 \%}$} & $\mathbf{7 5 \%}$ & \multicolumn{1}{c}{ Max } \\
\hline AP & 1005.97 & 0.66 & 1005.15 & 1005.47 & 1005.78 & 1006.39 & 1007.09 \\
RH & 85.71 & 1.43 & 83.26 & 84.92 & 85.68 & 86.88 & 87.97 \\
Min Temp. & 296.46 & 0.34 & 295.63 & 296.40 & 296.50 & 296.64 & 296.99 \\
MT & 304.10 & 0.38 & 303.61 & 303.81 & 303.96 & 304.41 & 304.83 \\
AT & 300.28 & 0.28 & 299.79 & 300.11 & 300.22 & 300.50 & 300.71 \\
DPT & 297.61 & 0.36 & 297.02 & 297.36 & 297.61 & 297.83 & 298.23 \\
SH & 0.95 & 0.00 & 0.95 & 0.95 & 0.95 & 0.95 & 0.95 \\
SVP & 35.94 & 0.57 & 34.92 & 35.59 & 35.82 & 36.30 & 36.88 \\
VP & 30.71 & 0.64 & 29.61 & 30.29 & 30.69 & 31.15 & 31.88 \\
SMR & 23.05 & 0.38 & 22.37 & 22.82 & 22.99 & 23.29 & 23.69 \\
MT & 19.59 & 0.42 & 18.87 & 19.31 & 19.57 & 19.90 & 20.37 \\
$T_{L}$ & 296.92 & 0.40 & 296.31 & 296.67 & 296.91 & 297.21 & 297.65 \\
PT & 299.77 & 0.25 & 299.29 & 299.63 & 299.77 & 299.93 & 300.25 \\
EPT & 357.37 & 1.46 & 354.61 & 356.25 & 357.35 & 358.27 & 359.94 \\
Refractivity & 387.11 & 2.44 & 383.38 & 385.64 & 386.97 & 388.86 & 391.57 \\
\hline
\end{tabular}


TABLE 5

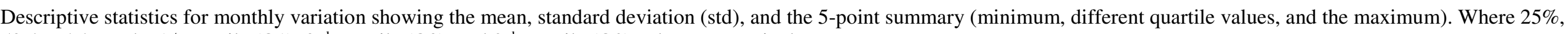
$50 \%, 75 \%$ are the $1^{\text {st }}$ quartile $(\mathrm{Q} 1), 2^{\text {nd }}$ quartile $(\mathrm{Q} 2)$, and $3^{\text {rd }}$ quartile $(\mathrm{Q} 3)$ values, respectively

\begin{tabular}{lrlrrrrr}
\hline Parameters & \multicolumn{1}{c}{ mean } & \multicolumn{1}{c}{ std } & \multicolumn{1}{c}{ min } & \multicolumn{1}{c}{$\mathbf{2 5 \%}$} & \multicolumn{1}{c}{$\mathbf{5 0 \%}$} & \multicolumn{1}{c}{$\mathbf{7 5 \%}$} & \multicolumn{1}{c}{ max } \\
\hline AP & 1005.97 & 1.24 & 1004.52 & 1005.01 & 1005.54 & 1006.92 & 1007.82 \\
RH & 85.71 & 6.98 & 70.63 & 84.96 & 88.54 & 90.03 & 91.81 \\
Min Temp. & 367.95 & 8.90 & 347.51 & 367.45 & 372.84 & 373.29 & 373.82 \\
MT & 412.03 & 9.81 & 396.16 & 405.01 & 412.44 & 418.15 & 425.93 \\
AT & 300.27 & 1.05 & 298.61 & 299.61 & 300.48 & 301.03 & 301.95 \\
DPT & 297.61 & 1.18 & 295.16 & 297.28 & 297.79 & 298.18 & 299.09 \\
SH & 0.95 & 0.00 & 0.94 & 0.95 & 0.95 & 0.95 & 0.96 \\
SVP & 35.94 & 2.21 & 32.53 & 34.51 & 36.32 & 37.50 & 39.56 \\
VP & 30.71 & 2.11 & 26.45 & 30.04 & 30.99 & 31.72 & 33.47 \\
SMR & 23.05 & 1.50 & 20.75 & 22.08 & 23.32 & 24.11 & 25.50 \\
MT & 19.59 & 1.39 & 16.81 & 19.11 & 19.78 & 20.26 & 21.44 \\
$T_{L}$ & 296.92 & 1.44 & 293.73 & 296.83 & 297.15 & 297.64 & 298.46 \\
PT & 299.77 & 1.15 & 297.96 & 299.03 & 300.02 & 300.60 & 301.56 \\
EPT & 357.37 & 4.68 & 350.13 & 353.84 & 357.18 & 360.93 & 364.57 \\
Refractivity & 387.11 & 8.55 & 368.08 & 386.59 & 388.69 & 391.53 & 396.03 \\
\hline
\end{tabular}




\section{Supplementary Files}

This is a list of supplementary files associated with this preprint. Click to download.

- GRAPHICALABSTRACT.docx 